\title{
Iranian superwomen's career experiences: a qualitative study
}

Maryam Nosrati Beigzadeh ${ }^{{ }^{*}} \mathbb{D}$, Hossein Ghamari Givi², Ali Rezaei Sharif², Ali Sheykholeslami², Leila Reisy ${ }^{3}$ and Hadi Hassankhani ${ }^{4}$

\begin{abstract}
Background: Superwoman refers to the identity of a woman who performs several important roles simultaneously and full-time, such as being a wife, mother, and homemaker while holding a job. This study aims to examine the career experiences of Iranian superwomen who maintained their mental health while holding multiple roles.

Methods: Data for this qualitative study were collected via semi-structured interview and analyzed using conventional content analysis. The study participants were 12 multi-role women from different occupations in Tabriz, North West of Iran selected through purposive and theoretical sampling. The women's mental health status was assessed using Mental Health Continuum-Short Form questionnaire before participating in the research.

Results: The results were classified into three main categories. The first category included Underlying Factors of Job Experience with six subcategories, including Limited job opportunities for women, Educational context (mindset shaped in the parental home), Commitment or freedom in obtaining a job and its continuation, Personality traits, and Non-cognitive skills (emotional intelligence and spiritual intelligence); the second category included the adopted strategies to solve career problems with two subcategories: effective strategies, including the benefits of having a mindset of abundance and having a vision and strategic planning, and ineffective strategies, including the benefits of having a mindset of scarcity; and the third category included Perceived Consequences of employment with two subcategories: psychological consequences and social consequences, with both subcategories including some positive and negative further subcategories. Moreover, a conceptual relationship between the main categories and the subcategories was evident.
\end{abstract}

Conclusions: The content obtained not only supports the findings about the experiences of multi-role women in cultures outside Iran, but also points to the unique aspects of Iranian superwomen's life experiences and narratives. The findings of this study can help us perceive the real career experiences from the perspective of Iranian professional women with multiple roles.

Keywords: Iranian superwomen's, Career experiences, Qualitative study

\section{Background}

Each individual's life experience is influenced by social and cultural beliefs, values, and unique life events. Life Experiences and challenges are a facilitating factor for

*Correspondence: m.nosrati.b@gmail.com

${ }^{1}$ University of Mohaghegh Ardabili, Ardabil, Iran

Full list of author information is available at the end of the article mental development and psychological resources have a significant impact on how people evaluate the challenges of their lives, how they cope with them, how they integrate them into their life story and ultimately create unique experiences [1] Research has shown that individuals' reflective narratives are critical to how they perceive important life events [2]. 
Several researchers in the field of occupational therapy also use narratives to examine people's life and work experiences $[3,4]$. In general, research on life-work experiences has expanded over the past five decades due to the tendency to change the nature of gender roles, family structure, and employment [5] Researchers have been studying the problems faced by mothers in the workforce for decades $[6,7]$. The idea of "participating in multiple roles simultaneously" or "doing it all together" in which women play a leading role has become a valuable social norm [8]. In the West, women's participation in multiple roles has been considered a key feature of their identity [9]. In Iran, on the other hand, there is still a dual perception of maternal employment, especially in certain professions. Iranian families are less likely to employ women in full-time or managerial jobs. The largest proportion of women's participation in the public sector belongs to the Ministries of Education (69.7\%) and Ministry of Health, Treatment and Medical Training (14/43\%), which shows the focus of women in the two professions of teaching and nursing, which are the continuation of the same female domestic jobs. Meanwhile, the proportion of women in the other ministries ranges from 0.02 to $4.9 \%$ [10]. "Superwoman" is a metaphor that refers to the identity of a woman who performs multiple important roles within marriage, motherhood, employment, and household responsibilities simultaneously and full-time [11]. In academic literature, "superwoman" is often described as a woman who holds multiple roles and is responsible for both employment and household responsibilities fulltime [12]. In Woods-Giscombé's research, a superwoman is a social phenomenon that has influenced the way African-American women experience. In this study, the following specific characteristics were introduced for the superwoman model: commitment to roles, experiencing stress, commitment to suppressing certain emotions, and helping others. The results of this study showed that women with Superwoman ideology experience both advantages and disadvantages. Advantages include being able to protect themselves and their family/club and having a sense of influence. Disadvantages include relationship pressure, emotional eating, poor sleep, and excessive levels of stress (anxiety, depression, poor mental health) [11].

Another study showed that the quality of roles in relation to the multiplicity of roles has a greater impact on mental health and quality of life. In other words, having multiple roles does not necessarily have a positive or negative effect on people's experience [8]. Therefore, the applicability of traditional gender roles to current gender roles or behavior is increasingly ambiguous between women and men [13]. A review of research on women's employment and their multiple roles reveals a number of similar perspectives and also theoretical differences that appear to be rooted in cultural and social differences. Moreover, no research could be located on the experiences and perspectives of Iranian superwomen in relation to their work.

In recent years, Iranian women have had new experiences related to their traditional roles and the conflict between traditional and modern expectations. And they play another role as working women in addition to the exclusive duties of motherhood and marriage. Despite the relative expansion of women's employment, the issue of multiple roles for Iranian women is still controversial. Therefore, the researcher needs to elicit the truth from the daily experiences of the participants in order to examine the many undiscovered facts in this regard [14]. So far, there has been a plethora of studies on the impact of employment on social and family relationships, but no research has been conducted to shed light on the professional life experience of Iranian superwomen from an exploratory perspective. Since employment is an important part of a superwoman's life, the nature of these women's perception and experience of their work is expected to play a significant role in other aspects of their lives. Accordingly, this study was conducted to explore the occupational experiences of Iranian women.

\section{Methods \\ Study Design}

A qualitative method with a conventional content analysis approach was used to conduct this study. The qualitative method emphasizes deep understanding, complexity, and details of the phenomena under study, and the researcher is actively involved in the research process. In conventional content analysis, most of the data are obtained through interviews, and interviews with individuals allow us to understand the experiences and perceptions of the participants and obtain richer data from their experiences [15]. Data were collected through semi-structured interviews based on the relevant literature [16-19]. The semi-structured in-depth interviews began with an openended question, "Considering that you have multiple roles, how would you describe your work life?" Exploratory questions were gradually used according to the participants' dialogs to extract further details and clarify the interviewees' explanations and examples. The questions also specifically aimed to elicit information about participants' perceptions of the concept of a woman's job, the concept of a superwoman, taking up a job, the reason for continuing the job despite having several other roles, and the strategies used to maintain a balance between personal and work life. These general questions were evaluated by five experts (Additional File 1). 


\section{Setting and participants}

Among the multi-role women living in Tabriz, northwestern Iran, 12 women who met the inclusion criteria were purposively selected. The inclusion criteria were that they had been employed for more than two consecutive years, were married with children, and were willing to participate in the study. Participants also completed the Mental Health Continuum-Short Form before taking part in the survey and could only participate if their score was above average $(p>50)$. Factor analysis revealed that the MHC-SF replicated the three-factor structure of emotional, psychological, and social well-being found in US samples. The internal reliability of the total MHCSF scale was 0.74 . The total MHC-SF score correlated 0.52 with a measure of positive affect, between 0.35 and 0.40 with measures of generalized self-efficacy and life satisfaction, and between 0.30 and 0.35 with measures of coping strategies, sense of coherence, and community collective self-efficacy. The total score of the MHCSF correlatedat 0.22 with the total score of the General Health. Questionnaire. In Iran, Khalili Vernakshi (2015) evaluated the psychometric properties of this scale in his research and its reliability was reported with a Cronbach's coefficient of more than 0.70 [20].

\section{Data collection}

Data collection began after receiving the Code of Ethics from the Ethics Committee of Iran-Ardabil University from Medical Sciences (IR. ARUMS. REC. 1398.552). The interviews were conducted between June and December 2019 in Persian language. Eleven women were initially interviewed. Due to data saturation, no new data emerged. However, another interview was followed up for confirmation and accuracy. Thus, the number of participants was twelve and the demographic characteristics included: occupation, employment history, education, age, marital history, number and age of children, and the score of their mental health questionnaire, which is shown in Table 1. The interviews provided relevant and valuable information and the depth of the descriptions was consistent with the purpose of the study. Therefore, this sample size was appropriate for this study and achieved theoretical saturation. Concurrent with the information gathering, analysis was conducted using the contractual content analysis method to identify "employment experiences." Content analysis focuses on the life experiences, interpretations and meanings that people face [21]. Each interview lasted between 60 and $140 \mathrm{~min}$ and all interviews were conducted by the researcher who had professional experience as a counselor. The researcher also made an effort to build a good relationship with the participants in individual sessions. After agreeing on the location of the interview (partly in the clinic and partly at the participants' workplace) and in order to adhere to the ethical principles of research, the purpose of the research and confidentiality were explained and informed consent was obtained to participate in the research and consent to record the dialogs through the protocol. The informed consent obtained was written and signed by each of the participants.

\section{Data analysis}

Data were analysis done manually by conventional qualitative content analysis. In this method, the analysis

Table 1 Demographic information of participants in the research

\begin{tabular}{|c|c|c|c|c|c|c|c|}
\hline Code & Job & Employment history (years) & Education & Age & $\begin{array}{l}\text { Marital } \\
\text { history } \\
\text { (years) }\end{array}$ & $\begin{array}{l}\text { Number and age } \\
\text { of children years } \\
\text { old }\end{array}$ & $\begin{array}{l}\text { Score of } \\
\text { mental health } \\
P>50\end{array}$ \\
\hline 1 & $\begin{array}{l}\text { Founder and principal of kinder- } \\
\text { garten }\end{array}$ & 9 & MA & 42 & 20 & $2(11 \& 18)$ & 67 \\
\hline 2 & $\begin{array}{l}\text { Founder and principal of non-profit } \\
\text { school }\end{array}$ & 4 & MA & 34 & 16 & $3(2,10 \& 13)$ & 61 \\
\hline 3 & Secretary & 7 (in the current job) & MA & 36 & 3 & 1 (15 months) & 55 \\
\hline 4 & Psychologist & 2 & MA & 37 & 22 & $2(15 \& 21)$ & 60 \\
\hline 5 & Teacher & 22 & BA & 44 & 22 & $2(12 \& 20)$ & 70 \\
\hline 6 & Lifeguard and sport coach & 16 & Ph.D & 35 & 10 & $1(4)$ & 63 \\
\hline 7 & Manager of a private company & 3 (in the current job) & MA & 50 & 30 & $2(27 \& 29)$ & 61 \\
\hline 8 & Computer teacher & 14 & $\mathrm{BA}$ & 38 & 11 & $1(3)$ & 50 \\
\hline 9 & Deputy principal & 29 & BA & 48 & 27 & $1(26)$ & 64 \\
\hline 10 & Theater actor & 18 & $\mathrm{BA}$ & 46 & 22 & $1(17)$ & 60 \\
\hline 11 & $\begin{array}{l}\text { Owner of a homemade food } \\
\text { restaurant }\end{array}$ & 6 & Diploma & 38 & 20 & $1(18)$ & 60 \\
\hline 12 & Nurse & 12 & Ph.D. student & 40 & 13 & $1(10)$ & 50 \\
\hline
\end{tabular}


was conducted simultaneously with data collection. In this method, codes and classes were extracted directly and inductively from the raw data. First, immediately after each interview, all conversations (including words, tone of voice, pauses, and laughter) were transcribed and typed. In order to increase credibility, the member- checking method was used. This means that the transcripts were presented to the participants (some of whom refused to read them) for comment. To complete the interviews, it was necessary to repeat some interviews. Then, the researcher extracted the semantic units and coded them in the form of initial codes by repeatedly reading the interviews. Using the constant comparison method, the collected data were coded, compared with other data and notes, and reduced into concepts and categories. The data were categorized and subthemes were formed by comparing similarities and dissimilarities of the codes and prolonged engagement with the data to provide a description of, increase understanding of, and gain knowledge about the phenomena under study; and finally, the latent content of the subthemes was formulated into a theme." Another way to assess the credibility of qualitative research is through "triangulation techniques". This method refers to the use of multiple data sources to present findings and overcome bias. In this research, diversity was considered in the selection of participants in terms of their occupation, role responsibilities (number and age of children), social status (occupation and education) and economic status (income and housing).

To ensure transferability, a full table of participant demographics, including job title, employment history, education level, age, marital status, number of children, and mental health questionnaire results, is provided (Table 1).

For consistency or trust, all raw information (recorded conversations, field notes, and interview texts) was retained and reproduced without attribution where necessary.

Finally, to increase credibility, the method of "researcher credit" was used. This means that the interviewer (first author) had sufficient experience in interviewing, interviewing, and conducting counseling interviews and had experience in conducting a qualitative research project. Also to increase credibility, a quote that matched the language and tone of the participant was provided.

\section{Results}

As can be seen in Table 2, the study included three main categories: underlying factors of work experience with six subcategories, strategies used to solve workplace

Table 2 Major categories, sub-categories and sub-themes related to Iranian women's job experience

\begin{tabular}{|c|c|c|c|}
\hline Main categories & \multicolumn{3}{|l|}{ Subcategories } \\
\hline \multirow[t]{7}{*}{ Contextual factors of job experience } & \multicolumn{3}{|c|}{ Limited job opportunities for women } \\
\hline & \multicolumn{3}{|c|}{ Educational context (mindset formed in birthparents'home) } \\
\hline & \multicolumn{3}{|c|}{ Obligation in getting a job and continuing it } \\
\hline & \multicolumn{3}{|c|}{ Freedom in getting a job and continuing it } \\
\hline & \multicolumn{3}{|l|}{ Personality characteristics } \\
\hline & \multirow[t]{2}{*}{ Non-cognitive abilities } & \multicolumn{2}{|l|}{ Spiritual intelligence } \\
\hline & & \multicolumn{2}{|l|}{ Emotional intelligence } \\
\hline \multirow{6}{*}{$\begin{array}{l}\text { Strategies adopted in solving job } \\
\text { problems }\end{array}$} & \multirow[t]{3}{*}{ Effective strategies } & \multirow{2}{*}{$\begin{array}{l}\text { Benefiting from abundance mental- } \\
\text { ity }\end{array}$} & Win-win thinking \\
\hline & & & Use of environmental potentials \\
\hline & & $\begin{array}{l}\text { Having a vision and strategic plan- } \\
\text { ning }\end{array}$ & Use of individual potential \\
\hline & \multirow[t]{3}{*}{ Ineffective strategies } & \multirow[t]{3}{*}{ Benefiting from scarcity mentality } & Lack of proper use of opportunities \\
\hline & & & Win-lose thinking \\
\hline & & & Fear of risk \\
\hline \multirow[t]{4}{*}{$\begin{array}{l}\text { Perceived consequences of employ- } \\
\text { ment }\end{array}$} & Psychological consequences & Positive consequences & $\begin{array}{l}\text { Independence, self-esteem, hap- } \\
\text { piness... }\end{array}$ \\
\hline & \multirow[t]{3}{*}{ Social consequences } & Negative consequences & $\begin{array}{l}\text { Feeling of jealousy, Lack of interest } \\
\text { in life Feelings of guilt, Feeling of } \\
\text { anger towards others, Feeling of } \\
\text { inadequacy }\end{array}$ \\
\hline & & Positive consequences & Social dignity \\
\hline & & Negative consequences & $\begin{array}{l}\text { Pressures from multi-role expecta- } \\
\text { tions, Perceived gender pressures }\end{array}$ \\
\hline
\end{tabular}


problems with two subcategories and several subthemes, and perceived consequences of employment with two subcategories and several subthemes.

\section{Underlying factors of work experience}

All participants confirmed that a number of background and underlying factors contributed to the formation of their work experiences. These factors were grouped into six main categories, including limited job opportunities for women, educational context (the mindset formed in the parental home), and obligation to find and continue a job, freedom to find and continue a job, personality traits, and non-cognitive skills.

\section{Educational context}

The prevailing culture and upbringing in childhood and adolescence influence many decisions and non-decisions in adulthood.

"... My mother was had job, and this mentality had been formed in me since childhood that a girl should be independent..." Participants 6, 9, 3, and 8.

"... My father always said that a girl should be financially independent so that her husband would not dominate her..." Participant 3.

\section{A commitment to getting a job and continuing in it}

Choosing a job without recognizing one's talents and desires, or based on a compulsion to choose and continue in the job due to existing constraints, has a direct impact on the quality of an individual's work experience.

"... I was eighteen at the time and I just did not know what I wanted. I just wanted to be independent ..." Participant 3.

"... If I had answered a few more questions on the entrance exam, I would be on a different path now ..." Participant 12.

\section{Freedom to get a job and continue with it}

In contrast, making a conscious decision and continuing out of personal interest and desire create different experiences for people.

"... If I were to go back in time, I would choose the same path again despite all the difficulties ..." Participants 9 and 6.

"... Our life does not depend on my income and I continue my job out of interest ..." Participants 10, 9,2 and 5.

\section{Limited job opportunities for women}

In developing countries, women have fewer employment opportunities than men and often work in the informal sector with low wages. In this study, some of the female participants believed that limited job opportunities influenced their work experience.

"...When I finished high school, I became a teacher, as is the custom for girls in our village. This job is more suitable for a woman ..." Participant 5.

"... After I got my master's degree, I worked in different places, but I came to the conclusion that my field was male and men had priority in hiring ... I ended up having to work in a job that had nothing to do with my education ..." Participant 8.

\section{Personality characteristics}

Personality characteristics or personality traits are an important underlying factor in determining personal and organizational behaviors. We saw common personality traits in a number of participants that can be divided into two subcategories: Personality Strengths or positive personality traits and Personality Weaknesses or negative personality traits.

\section{Positive personality traits}

Some of the participants in this study had several positive personality traits including:

Persistence: "... I have worked hard to get to my current position. I continued my education while my family and husband were in another city and I had a young child and was pregnant with my second child ..." Participant 2; Liveliness and humor: "... All my colleagues notice when I do not go to work for a day because I try really hard to be warm and lighten up the gloomy atmosphere with jokes ..." Participants 6 and 5; Discipline: ".. My work schedules always go in a certain order so that if I can not go to work, my deputy knows what she has to do that day ..." Participant 2; Seeking novelty and exploration: "... I remember being curious as a child ..., I am the same in my job and I look for the latest topics ..." Participant 5; Optimism: ".. It's true that I do not have a high professional position and it's in the service category, but I am really satisfied that the customers leave this place with satisfaction" Participant 3; And hope "... the only thing that kept me going in these difficult times was my hope to achieve my long-term goals ..." Participant 9. 


\section{Negative personality traits}

A distinct list of personality weaknesses expressed by participants who believed such traits could play a direct role in the work experience included:

\section{Excessive use of some defense mechanisms}

Denial of the problem, projection of the problem, and avoidance of problem solving were among the defense mechanisms mentioned.

\begin{abstract}
Avoidance: "... I did not follow it. The system is flawed and it can not be solved ..." Participant 8; Projection: "... I think that someone who was able to get what he/she wanted must have either a sorority or a rich husband ..." Participant 7; Denial: "... I do not think about thing that nervous me!" Participant 3.
\end{abstract}

\section{Lack of discipline}

Lack of discipline in the sense of orderliness and conscientiousness is one of the personality factors in the development of vocational experiences: "... My life situation gets out of hand when I act at the last minute, and it has little to do with lack of time. I think it's kind of a personality trait because it's the same on off days" Participant 4.

\section{Self-doubt or lack of confidence in others}

Some of the narratives indicate pessimism and lack of confidence in self or others: '... It has nothing to do with the behavior of my colleagues. I just cannot trust them or be very close to them ..." Participant 8.

Self-doubt: ".. How effective can a person be in a small work environment?" Participant 7.

\section{Laziness and Indolence}

Laziness and indolence was another personality weakness reported in the narratives:

I am lazy to do some work. I do not even know how time passes.

\section{Do not want more}

Do not want more or being content is another personality factor observed in people who, under the guise of being satisfied with what they have, do not put in more effort and do not set long-term goals. These people are usually not motivated to progress and improve.

"... Insurance was the only thing that mattered to me. Although my professional position has nothing to do with my education, I am satisfied ..." Participant 3.

\section{Non-cognitive skills}

Non-cognitive abilities refer to constructs beyond cognitive intelligence and learning. Non-cognitive aspects of intelligence include emotional, social, and other skills. The data in this study are based on the two categories of emotional intelligence and spiritual intelligence.

\section{Emotional Intelligence}

The basic components of emotional intelligence, including the ability to understand one's own emotions and those of others and to relate to others, were saturated in the statements of the participants in this study.

"... At that moment I just tried to put myself in my boss's shoes ..." Participant 9.

"... I am known among my colleagues to be adaptable..." Participant 10.

\section{Spiritual intelligence}

Using spiritual intelligence, people define a "why" for their lives so they can make an effective "how." Concepts such as professional ethics, belief in a superior processor power, honesty, conscientiousness, and a search for meaning in work are included in the definition of spiritual intelligence. To explain, we will use some examples from the participants'narratives: "... I made a promise to perform wholeheartedly on stage to help people feel better about themselves..." Participant 10. "... My work is valuable to me because I want to untie the knot of people's problems ..." Participant 4. They talk about professional conscience and values of professional ethics: "... I was repeatedly offered bribes and I needed the money but I did not take it ..." Participant 1 . Or they make a personal meaning for their profession: "... Maybe not from the beginning, but soon after I was hired, my job made sense to me. I was no longer so results oriented and did not think like some of my colleagues that I should work as much as my income and the process became rewarding for me ...".

\section{Adopted strategies in Solving Job Issues}

The second major class of codes related to the strategies adopted by a superwoman in dealing with her professional problems. These strategies were divided into two subcategories: effective strategies and ineffective strategies. The subcategories of her effective strategies were divided into two subcategories: Profiting from Abundance Mentality and Creating a Job Perspective and Strategic Plan: 


\section{Profiting from abundance mentality}

The key principle of the abundance mentality is that resources are available to all, and the more you help others, the more you are helped. In a way, the difference between successful and less successful people depends on such mentality. According to this definition, the participants' performance was divided into three subcategories:

\section{Have win-win thinking}

Win-win thinking is a mindset that constantly strives to create mutual interest in all aspects of communication, and it is based on the principle that everything is abundant for everyone in the universe. It also means that one person's success does not depend on another's failure.

"Being destitute does not worry me much. I believe that God blesses us. We have this view in our religion that if you wish well for others, you will have the blessing..." Participant 1.

".. He was my competitor, but when he asked me for advice, I gave him all my experience as a founder ..." Participant 2.

\section{Harnessing environmental potential}

People who have an abundance mentality trust others and use the experiences of successful people and make the most of the least environmental potential.

"I always try to listen and participate in research projects as determined by the administration." Participant 5.

These people believe that unity is not defined by being one, but by being complementary, with one's weaknesses being compensated for by the strengths of others.

"...Even the smallest ideas I received at group meetings were taken seriously and I thought about them. After a while my staff took the meetings more seriously and we now have good collective participation in our school ..." Participant 1.

"... I never thought that my idea is ineffective in the group because I am not the boss. I say what comes to my mind about the progress of the company ..." Participant 3.

\section{Using individual potentials and trying to acquire more skills} People with an abundance mentality are not afraid of the unknown and believe that anything is possible. They overcome their fears and focus their thoughts on what they have, not what they do not have. They do not derive their feelings of peace and security from the beliefs of others and material possessions and do not depend on external factors. Therefore, external events do not have a strong influence on their inner stability, as they rely on their own abilities. "... Some people think that if the management changes, their job situation will change a lot, but these things are not important to me. I do my job well ..." Participant 9. "... Well, the situation there was not good and everyone was used to it ... I finally decided to leave there. Great things happen when you stop changing your environment and focus on yourself ... After that, I thought about starting a clinic and putting my energy into it ... Now the situation is very different ..." Participant 4.

\section{Have a vision and plan strategically}

The thinking style of some individuals resembles reverse engineering and a comparative perspective. Such individuals first paint a clear picture of their long-term career goals and then move on to smaller goals and daily tasks and have a clear and defined path they want to achieve. These people do not suffer from indecision or doubt when making career decisions.

"... I even have a plan for when I retire ..." Participant 1. "... Since I have been in this job, I have sat down and written down where I want to go and set my goals in the form of long and medium term plans. I also plan daily based on these goals ..." Participant 5.

\section{Ineffective strategies in solving work problems}

In the participants' narratives, we noticed the use of some ineffective strategies in solving work problems. We grouped these strategies into a category called "profiting from a scarcity mentality." This subcategory itself could be divided into three separate subthemes.

\section{Profiting from a scarcity mentality}

People with a scarcity mentality believe that there is only a limited amount of everything, and the more others benefit from that limited amount, the smaller their share will be. The narratives of individuals whose strategies in various work situations were influenced by this view could be divided into the following three subcategories:

\section{Win-lose thinking}

The fundamental belief in a work environment that evolves on the basis of scarcity mentality is that competition leads to survival of the best. According to this thinking, people view someone else's victory as their own 
failure and suffer greatly from the sharing of privilege, credibility of power, and the benefit of others.

"... I constantly check the number of customers of other companies and compare them with our company. The situation is disappointing. Companies are growing fast ..." Participant 7.

"... Unfortunately, some of the founders of the nonprofit centers do not act openly because they think that if you help, you expose yourself and your competitor will quickly take your place..." Participant 2.

\section{Lack of opportunity}

People with a scarcity mentality constantly look at the progress of others and try to reassure themselves with various excuses that leave no room for seeing what they themselves have. Thus, they do not take advantage of a single opportunity. An example of this is:

"... Can I think of promotion with this minimum income? Those who attend these skill courses must either have rich husbands or have no financial needs..." Participant 8.

\section{Fear of risk}

Win-lose thinking style leads to fear of failure and rejection because people's decisions are influenced by scarcity mentality and competitive attitude, not by personal skills. Such people are not interested in taking the risk and are more interested in safety.

"... I have not thought about promotion because it's high risk. At the moment at least I have a fixed salary and I do not want the situation to change ..." Participant 3.

\section{Perceived consequences}

Each of the participants indicated in their narratives that employment has consequences for them. These consequences could be divided into two subcategories of positive and negative consequences, and each subcategory was then divided into two smaller subthemes labeled positive and negative social consequences and positive and negative psychological consequences.

\section{Positive social consequences}

In recent decades, cultural and social changes in Iran, along with increased awareness and skills, have made employment a social demand for some women. Women's employment has increased their income and consequently increased their access to social capital such as education, hygiene, recreation, and improvement in the Human Development Index and shaped their social identity.

\section{Social dignity}

The women in this study who were satisfied with their current situation despite the multiple challenges confirmed that they perceived more social dignity from their environment than before employment.

"... Most women look at me with admiration and ask me how I can manage all these roles, especially when I have a young child ..." Participant 2 "... I feel that I have gained the absolute trust of my husband and the people around me because I have shown my abilities in several roles. They ask me for advice on their own problems and accept me as a counselor ..." Participation 5.

\section{Positive psychological outcomes}

Feeling productive and having professional success can fulfill some of the psychological needs of humans. In addition to positive social consequences, this group of participants shared common experiences of positive psychological consequences. These consequences were categorized as positive emotions from employment.

"... This work gives me a sense of dignity and worth

..." Participant 1, "... I feel independent and free in my actions ..." Participant 6, 9, 2 and 1.

\section{Negative social consequences}

In contrast, some of the participants shared experiences of negative social consequences of being multi-role. These narratives are perceived as two sub-categories: perceived gender pressures and pressures resulting from multi-role expectations.

\section{Perceived Gender Pressures}

In the modern world and with the evolution of public consciousness, gender role attachment has become less important, especially for women, and factors such as women's desire for social status and their pursuit of academic specializations and professional skills are intertwined. At the same time, gender inequality and sometimes violence against women in the workplace are perceived in various forms. Here are some examples of these statements:

"... If I were not a woman, I would make more progress in my career ..." Participant 11.

"Some women flirt and the boss helps them with their work. But I am self-possessed and behave in a serious way, so I always lag behind my other col- 
leagues..." Participant 2.

"...I have worked in a few other jobs and after a while

I realized that the environment was not safe at all. I mean my bosses were staring at me with googly eyes, which was really annoying and made me leave my job immediately..." Participant 3.

\section{Pressure from multi-role expectations}

Women are required to take on other roles in addition to their job responsibilities, such as raising children and maintaining a family network. Having multiple important roles can lead to role conflict and the resulting pressure. This conflict can be caused or exacerbated by job pressures, inflexible working hours, an increased number of working hours, and lack of support from those around them, unequal sharing of household tasks and caring for a young child or the elderly.

"... I was not an official employee, I would have lost my job if I had gone on maternity leave, so I had to go to work until the last days of my pregnancy ..." Participant 3. "... I feel like I am ignoring myself in order to keep going. I ignore my needs for fun, recrea- tion, free time, etc. ..." Participant 10.

\section{Negative psychological consequences}

Women's dissatisfaction with their status and role has increased as they have become more involved in society. The consequences of this dissatisfaction may take the form of passive responses such as emotional distress and stress. Participants in this study reported the following:

Feelings of jealousy "... sometimes you get jealous because you always see your colleague's life ..." Participant 8.

Lack of interest "... I would not have gone on if I had not had to, and I would have let go of that chronic tension ..." Participant 12.

Feelings of anger towards others "... some of my female colleague's have not own bank cards, which means they do not have the right to spend their own income. Such women really need to be helped mentally, and I see how badly they are doing...".

Feelings of inadequacy "I am always stressed and I do not feel good enough in this job..." Participant 7. Feelings of guilt "... When I first put my child in kin-

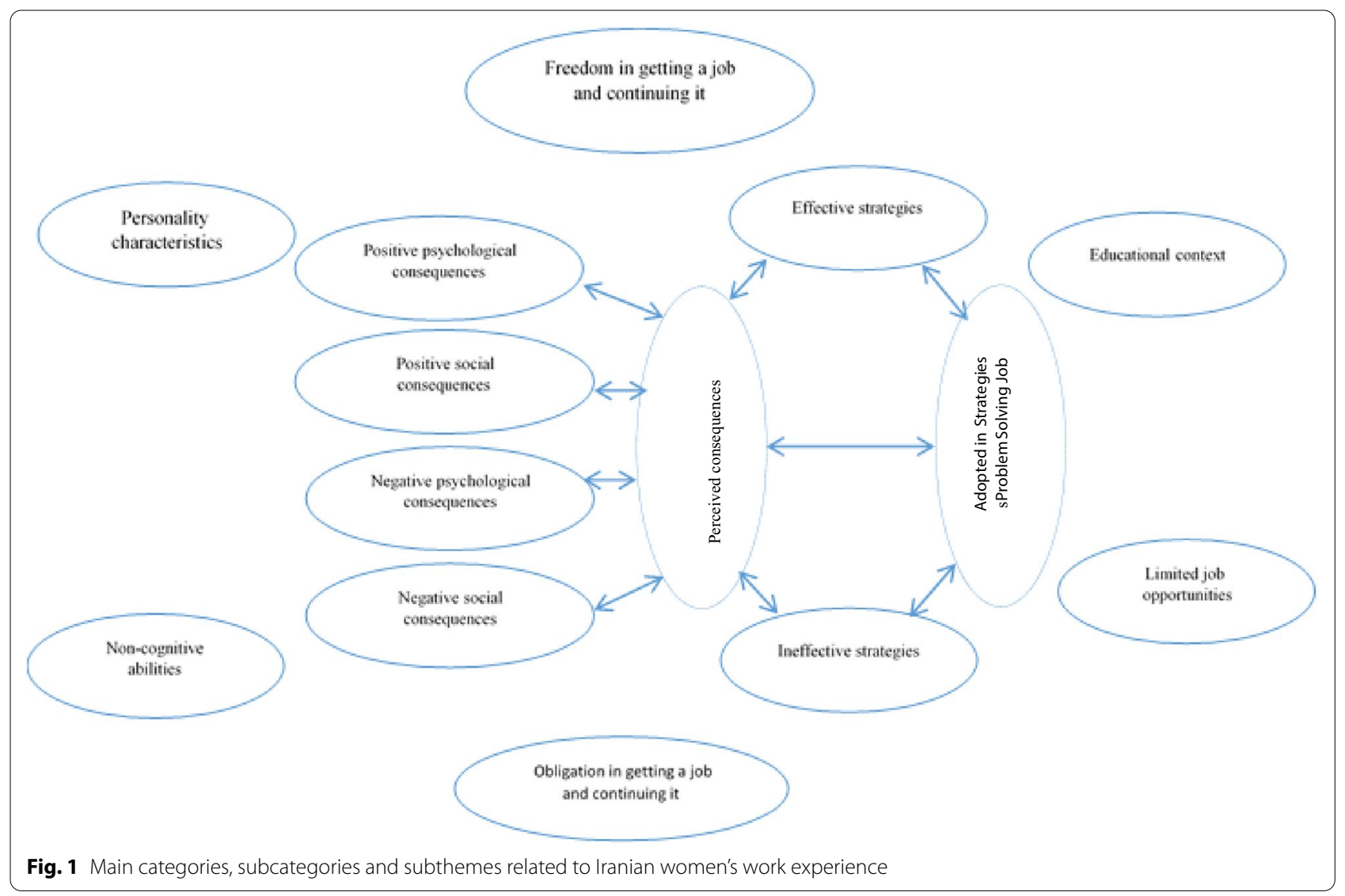


dergarten and then went to work, I hated myself and wondered, what's the point of teaching so many children when my own child is crying in kindergarten?" Participant 1.

After a brief review of the categories obtained and rereading the interviews, a circular relationship between the categories emerged (Fig. 1). It can be concluded that based on the concepts extracted from the data, the life experiences of the multi-role professional women who participated in this study were influenced by six underlying factors that in some way affected their choice of professional problem-solving strategies. This had a reciprocal effect on the shaping of occupational experiences and the psychological and social consequences of those experiences (Fig. 1). The following examples from participant (9)'s narratives reflect this relationship:

"...As a child, my financial independence was important to my parents ... (educational context) ... Although it was very difficult, if I went back in time I would choose the same career path again ... (freedom of choice) ... Anyone who hears my life story cannot believe that a woman can show such perseverance to try to keep her job despite all obstacles... I was very hopeful in those days and also optimistic about the future ... My food was prepared earlier than that of our neighbor who was a housewife, and I always had a certain order of doing things ... (Personality traits) ... there are moments when you would not really expect it, but you have to make a decision right away that is the best choice at that moment ... (emotional intelligence) I never thought of not paying much attention to my job because of the low salary. I had a personal purpose for all the extra activities I did ... (spiritual intelligence) ... I worked around the clock so I could make the most of the opportunities the office gave me to help raise our school's sports teams. We always won and my efforts paid off... There were always people who wanted to throw stones, but I did my job ... (Abundance mentality) ... My son says that he is proud to have such an active mother ... My parents are proud of me too ... My husband has always talked about my abilities ... (social implications) ... It gives me a special sense of pride and self-esteem and one becomes more hopeful to go on and be sure that it was worth choosing this path ... (psychological consequences)"

\section{Discussion}

The findings of this study can help us understand the real life work experience from the perspective of working women. The themes obtained point to the unique aspects of Iranian superwomen's life experiences and narratives and also support the findings on women's experiences of multiple roles in transnational cultures. What distinguishes the data of this study from the findings of studies on non-Iranian superwomen are the influence of the underlying contexts on shaping their professional experiences. The underlying contexts of this study included educational context, freedom or obligation to get and continue a job, personality traits, and constraints in job opportunities, and non-cognitive skills, which to some extent influenced the selection of problem-solving strategies in the workplace. On the other hand, the strategies chosen had a significant impact on positive or negative psychological and social consequences that resulted.

Participants in the present study felt that the educational context and prevailing attitudes in the home had either a positive or negative influence on the motivation and quality of their work experience. As Murdouk notes in his book, "some women find that their efforts to succeed and gain the approval of others are based on the satisfaction of their parents, especially the inner father." Jung's analytical psychology theory states that such women, who hold the title of "superwomen" but mimic the "men's championship journey" model, have only two choices; either they must compete hard in the male-dominated culture and become "successful" or they become dominated and dependent. But this theory also proposes a third way, which is to "live fully as a woman and enjoy your whole being and position in the universe" [22]. In explaining the underlying category of freedom or obligation in taking up and continuing work, it can be stated that Iranian women are not legally barred from participating in economic activities and they have full control over their economic affairs from the perspective of religion [23]; however, some factors influence their participation or non-participation in society. The present study has tried to discover these factors. In recent years, Iran has seen a sharp increase in inflation and a sharp decrease in the purchasing power of families, to which men's sole income cannot respond. Therefore, some women are forced to enter the labour market and earn money. People in forced labour pay scant attention to their professional preferences and interests. Subsequently, they make decision based on coercion and the economic conditions which they are entangled with. This finding is consistent with sociological theories of occupational choice. Among the adherents of this theory are Caplow, Miller, and Form $[24,25]$. This forced employment in the absence of proper supportive institutions (such as the lack of appropriate 
conditions for pregnant or lactating mothers and young children, the lack of promotion of the culture of men's participation at home, etc.) has doubled the pressure of multiple roles for women, leaving them without positive experiences of their work. Recognising the importance of institutional support, the latest findings (2019) show that we are now seeing competition in the provision of extended paternity leave and other "family-friendly" benefits to attract and retain young people in companies that rely on young talent [5]. Given flowchart \#1, superwomen who continue to work under coercive conditions rather than at their own discretion and interest can be expected to fail to use effective strategies to solve their multi-role problems and, as a result, face negative psychological and social consequences. Straiton et al. [26] indicated in their qualitative research that working women use maladaptive coping strategies such as avoidance to deal with feelings of guilt over their absence as mothers, work stress, and other pressures from the competitive world of work. The ineffective strategies reported in this study were classified into three subcategories: Fear of risk, a competitive mentality based on win-lose thinking, and failure to take appropriate advantage of opportunities. All three subcategories were in the main category called scarcity mentality. Studies have divided the work vision characteristics of individuals into two categories: Abundance Mentality and Scarcity Mentality. People with scarcity mentality cannot accept or enjoy the success of others [27]. Underlying the scarcity mentality is the belief that competition leads to survival of the fittest. This mindset is closely related to win-lose thinking and influences people's decisions, depriving them of the opportunity to take risks and make progress [27]. Moreover, despite their constant thinking of their own interests, they miss many opportunities for progress in the environment because they do not trust others and see life as if they do not have many options. Studies have shown that people with a scarcity mentality only feel good about themselves when they are better than others [28]. Therefore, it is predictable that these people will always face a series of negative consequences. In this study, participants who used this type of mentality to solve their professional challenges and worries attributed the reason for success to other factors such as luck, connection, rule breaking, etc. Such responses are known in psychoanalysis as defense mechanisms of denial and projection. However, when asked deeper questions, they eventually admitted that they felt envious of successful people or that they were in a kind of competition with them, constantly comparing their shortcomings with those of others. In this study, we observed the effect of another underlying factor called negative personality traits, which plays a role in women's choice of strategies. According to the studies on the concept of scarcity mentality, win-lose thinking leads to fear of failure and rejection, which has a strong negative impact on the quality of relationships while leading to negative perceptions and inadequacies. Therefore, in interpersonal relationships we see intense anger and competition to eliminate the other, and in intrapersonal relationships constant despair, worry, and dissatisfaction with oneself [29]. In the present study, a number of reports identified feelings of jealousy and anger toward others, feelings of inadequacy toward oneself, guilt, and feelings of disinterest toward work. We also witnessed this flawed view of "superiority to housewives" among the participants with a scarcity mentality. Likewise, this finding seems to have arisen under the influence of the unique sociocultural factors, and in some ways, rooted in the notion that these people viewed housework as an insult and a disgrace to themselves.These themes are classified under the category of negative psychological consequences. As shown in the flowchart, it is clear that these negatively perceived consequences can have a reciprocal effect on work performance and the choice of more ineffective strategies. But in addition to negative psychological consequences, narratives of perceptions of negative social consequences were obtained: including two subcategories of perceived gender pressure and pressure resulting from multiple role expectations (Table 2). Indeed, gender is a significant variable in many work-family studies [29, 30], but perceptions of gender pressure for a particular group may be influenced by the characteristics of the context studied. In the present study, some of participants believed that multiple roles, gender characteristics, and the dominant cultural and social context in Iranian families limited their career opportunities and influenced their work experiences. This cultural context creates a sense of failure and leads the Iranian professional women in such a context to spend their entire working lives trying to achieve a leadership position and, when they are forced to give it up or do not get it, they feel defeated and dissatisfied. However, Powell (2018) argued that since the 1970s, gender segregation has declined in most countries due to the increasing employment of women in managerial and professional occupations [31]. According to a social approach, the traits and behaviors of individuals are determined by their gender, and none of the behavioral traits are inherently masculine or feminine, but it is the society and the dominant culture that determine the traits of gender [32]. As we observed in this study, some of the occupations are considered more suitable for women with multiple roles.

Some saw popular grouping as a form of social discrimination and an obstacle to the realisation of their particular dreams. They believed that one of the limitations to getting a job for a woman was gender segregation 
because it made many environments unsafe and sometimes impossible for a woman to work. According to the participants, a set of unwritten rules based on gender directs women's participation in society, and women who move outside of this direction face intense social pressure. As many studies have shown, preoccupation with gender stereotypes affects people's mental health and impairs their social functioning [33-35].

In explaining the subcategory of the stresses of multirole expectations, participants acknowledged that working women still play a key role in caregiving, parenting, and household tasks. In a meta-analysis, Shockle et al. (2017) showed that most people view coping with housework as a gendered problem [36]. Recent research shows that working mothers face high maternity norms [37-39], unfair parental leave policies [40], and discrimination in the division of domestic tasks while managing their life tasks and responsibilities within the dominant culture [41]. In Islam and the Iranian legal system, men are expected to pay for family expenses, and women do not have the duty or responsibility to provide for household expenses [42], and even non-working women are not required to do household chores [43-45], but obviously the social roots of patriarchy are stronger than the religious and legal foundations and have permeated the institution of most families.

In some of the narratives of the participants in this study, we heard complaints about the lack of cooperation from the spouse or other family members and the pressure that comes from these expectations. These accounts are consistent with approaches such as role multiplicity, role conflict, and multiple role strain, which suggest that expectations and pressures resulting from multiple concurrent roles threaten the mental health of working women [46]. Limited energy and time constraints can lead to role conflict and role overload, resulting in stress and poor mental health [47]. Egyptian researchers have shown that economic pressures on the family have led Egyptian women to seek employment in recent decades; however, cultural values continue to support traditional roles. Therefore, for Egyptian women, seeking a job and entering a multi-role world leads to negative emotions and fear of neglecting main roles [48]. On the other hand, research has shown that experiencing multiple roles can lower stress levels because women experience organizing themselves to manage multiple roles [49]. Many studies have shown that employment is an important determinant of health and life expectancy [50] [51, 52]. The results of these studies are consistent with the present study on the reported positive social and psychological outcomes and can be explained in accordance with the role expansion hypothesis. This hypothesis states that multiple responsibilities and roles lead to social support, self-esteem, social dignity, and increased mental health through the expansion of the communicationnet work [53]. The positive psychological and social consequences of this study were the result of using effective strategies to solve work problems (Fig. 1). These strategies were divided into two categories: Using an abundance mentality and Having a vision and strategic planning. Abundance mentality leads to taking advantage of opportunities, focusing on one's own abilities, being interested in contributing to collective progress, not being afraid of failure and occupational risks, and thus not suffering from psychological distress, anxiety, and worry caused by comparing oneself to others, blaming oneself, or reflecting on the successes of others [54]. The abundance mentality can help improve a person's performance by reducing their stress and anxiety [55]. The studies and research conducted confirm the above positive effects of an abundance mentality on people's work performance and mental state $[56,57]$.

The second effective strategy presented in the experiences of the superwomen in this research is determining the career vision and mission and the plan to achieve it (Table 2). The participants who were interested in a job and were free confirmed that they could relax and recover by giving meaning to their career and despite the multi-role challenges. Most of them defined a meaningful mission and goal for their job and tried to achieve it. Studies on the mission of career path and emphasis on the meaning of employment have been conducted since 2007 and have increased in recent years [58]. Examples include the research by Bunderson and Thomson. Their results show that career issuance has a significant negative relationship with high levels of depression [59]. In addition, Duffy and Dik found that career issue has an insignificant relationship with intention to leave the job and a moderate relationship with job commitment, job satisfaction, and organizational commitment [58].

Qualitative research has introduced a five-stage framework for career issuance that ultimately leads to an invaluable work experience [60]. To further explain the category of "effective strategies" and discover its consistency with the pioneering global research, we will explain the two underlying and influential categories in the choice of effective strategies in the work experiences of the superwomen in our research. The participants confirmed that the two categories of "non-cognitive skills" and "personality traits" are among the underlying factors of women's work experiences (Flowchart 1). Following the introduction of the psychological concept of cognitive intelligence in the world of work, the study showed that people do not only enter the labor market with their bodies and minds. They also bring their own unique personal talents [61]. In this study, non-cognitive skills were 
divided into two subcategories of emotional intelligence and spiritual intelligence. Emotional intelligence is a set of non-cognitive skills that influence an individual's ability to cope with social demands and pressures [62], and it is a key factor in success in school, work, and social settings [63].

Another study concluded that people with high emotional intelligence have higher job satisfaction and organizational commitment and are less likely to suffer from job burnout compared to others [61]. Following the concept of emotional intelligence in the workplace, numerous studies have shown that there are successful organizations today that adapt to different conditions and only organizations that have employees with high spiritual power can act in this way [64]. Spiritual intelligence in the work environment has increased efficiency and productivity [65] and has a positive and significant relationship with physical, mental and social health [66]. Another research reported a significant relationship between employees' spiritual intelligence, spiritual and mental happiness, organizational effectiveness, and increased performance [67]. In line with the findings of the present study, Unterrainer et al. showed in their review paper that spirituality is associated with the enhancement of psychological and personality components [68].

Personality traits are another underlying factor introduced in the present study. Participants argued that superwomen who address their problems and challenges arising from multi-role conflicts with effective strategies and ultimately have a positive and satisfying experience with their careers share a number of personality traits. Participants identified and expressed these traits in themselves or others. The traits most frequently mentioned in the interviews included: seeking novelty and curiosity, humor, optimism and hope, discipline, and perseverance. These results are consistent with the research of Alterman et al. who showed that individuals who score high on the Openness personality trait are curious about the inner and outer world and their lives are rich in inexperience.

In addition, these individuals are less exposed to stress than their counterparts. The results of this study suggest a negative relationship between the Openness personality trait and individual and organizational stress [11]. In explaining the effect of the personality factor of humor, we can point to a more comprehensive personality trait such as extroversion, in which individuals are distinguished based on their interest in others, preference for large groups, courage, activity, conversationalist, cheerfulness, and humor, optimism, determination, and enthusiasm. This outstanding trait makes these people less stressed in the workplace. In addition, such individuals are more likely to have a positive outlook on their future careers and personal competence. This positive cognition and perspective prevent the emergence of negative psychological conditions such as frustration, fatigue and ultimately job stress [12] also, people who have the personality traits of conscientiousness and discipline are accurate, punctual, and reliable, and have high, pre-determined goals and desires. Moreover, people with high scores in this category are conscientious, purposeful, efficient, and determined. It's been shown that high scores on conscientiousness are associated with job and academic success. Other characteristics of these people are accuracy, punctuality, and striving for success and discipline [69].

\section{Limitation and suggestion}

The present study is limited to describing the experiences of volunteer participants in the cultural context of East Azerbaijan Province. Therefore, the focus of the present study was on a specific context and sample, and such limitations restrict the generalization of the findings to other contexts and ethnic groups. It is recommended that this study be replicated in other contexts and cultures in our country and with other samples. This study provides important themes for experts and researchers to take effective action in providing educational protocols to improve the lives of women with multiple roles by identifying their concerns, challenges, strategies, and the consequences of the choices they face.

\section{Conclusion}

This study is an in-depth investigation of the life experiences of Iranian superwomen, which has also shed light on the paradoxes of these experiences. According to the findings of this study, Iranian superwomen have different work experiences depending on limited work opportunities, the form of educational context and background, compulsory or voluntary employment, personality traits, and non-cognitive skills. Applied strategies of superwomen lead to the perception of different outcomes in solving job challenges, all of which affect the formation of job experiences and ultimately the choice of their next strategies. The present study was conducted knowing the importance of women's role in the three important positions of marriage, motherhood and job. It is worth mentioning that the perception of a super woman's job experience depends on how she plays her multiple roles.

Since there was no in-depth study on the work experiences of Iranian superwomen, we tried to conduct an exploratory qualitative study on the participants' life experiences considering their cultural background. We have not found any other research that accurately 
addresses the female multi-role community in Iran and other countries and shows the uniqueness of the participants' shared experiences. We also observed a mutual relationship between these categories and tried to show and explain this in the form of a flowchart.

\section{Abbreviations}

MHC-SF: mental health continuum-short form.

\section{Supplementary Information}

The online version contains supplementary material available at https://doi. org/10.1186/s12905-021-01369-3.

Additional file 1. The main interview questions.

\section{Acknowledgements}

The authors thank the participants for sharing their experiences.

\section{Authors' contributions}

MNB: Resources, Investigation, Writing —original draft, Writing—review and editing, Designing interview questions, conducting interviews, Data analysis and coding. HGK: Confirmation of interview questions, provided critical revision of the article, provided final approval of the version to Submit. AR: provided critical revision of the article, Confirmation of interview questions, Data analysis, and coding. ASh: Data analysis and coding. LR: provided critical revision of the article, Data analysis, and coding. HH: Contributed substantially to the conception and design of the study and the analysis and interpretation, provided final approval of the version to Submit, Data analysis and coding. All authors read and approved the final manuscript.

\section{Funding}

No funding to declare.

\section{Availability of data and materials}

The datasets used or analyzed in the current study are available from the corresponding author upon reasonable request, but the interviews and all coding steps are in Persian and require translation.

\section{Declarations}

\section{Ethics approval and consent to participate}

After receiving the ethical code (IR.ARUMS. REC.1398.552) from the Ethics Committee of Iran-Ardabil University from Medical Sciences. All the interviews were conducted by the counsellor who had counselling experience. The researcher also made efforts to establish a good relationship with the participants in individual sessions. After agreeing on the location of the interview (some at the clinic and some at the participants' workplace) and to adhere to the ethical principles of research, the purpose of the research and confidentiality were explained and informed consent was obtained to participate in the research and consent to record the dialogues through the protocol. The informed consent obtained was written and signed by each of the participants.

\section{Consent for publication}

Not applicable.

\section{Competing interests}

The authors do not declare any conflict of interest over the research presented in the paper.

\section{Author details}

${ }^{1}$ University of Mohaghegh Ardabili, Ardabil, Iran. ${ }^{2}$ Department of Counseling, Faculty of Education and Psychology, University of Mohaghegh Ardabili, Ardabil, Iran. ${ }^{3}$ Department of Midwifery, School of Nursing and Midwifery, Ardabil
University of Medical Science, Ardabil, Iran. ${ }^{4}$ Department of Nursing, Nursing and Midwifery Faculty, Tabriz University of Medical Sciences, Tabriz, Iran.

Received: 16 October 2020 Accepted: 23 May 2021

Published online: 31 May 2021

\section{References}

1. Glück J, Bluck S, Weststrate NM. More on the MORE life experience model: what we have learned (so far). J Value Inquiry. 2019;53(3):349-70.

2. Jonsson H, Josephsson S, Kielhofner G. Narratives and experience in an occupational transition: a longitudinal study of the retirement process. Am J Occup Ther. 2001;55(4):424-32.

3. Clouston T. Narrative methods: Talk, listening and representation. Br J Occup Ther. 2003;66(4):136-42.

4. Molineux M, Richard W. Storied approaches to understanding occupation. J Occup Sci. 2003;10(1):52-60.

5. Powell GN, Greenhaus JH, Allen TD, Johnson RE. Introduction to special topic forum: Advancing and expanding work-life theory from multiple perspectives. Acad Manag Rev. 2019;44(1):54-71.

6. Hewlett SA, Luce CB. Extreme jobs: the dangerous allure of the 70-hour workweek. Harv Bus Rev. 2006;84(12):49-59.

7. Williams JC, Segal N. Beyond the maternal wall: relief for family caregivers who are discriminated against on the job. Harv Women's LJ. 2003;26:77.

8. Sumra MK, Schillaci MA. Stress and the multiple-role woman: taking a closer look at the "Superwoman." PLoS ONE. 2015;10(3):e0120952.

9. Heather AK. Young women constructing identities: Multiple subject positions and the superwoman ideal. University of Calgary, 2008.

10. T. Statistics Center of Iran (2016). Abstract Results of Labor Force Statistics, Summer 2016

11. Woods-Giscombé CL. Superwoman schema: African American women's views on stress, strength, and health. Qual Health Res. 2010;20(5):668-83.

12. Alterman T, Grosch J, Chen X, Chrislip D, Petersen M, Krieg E Jr, Chung $\mathrm{H}$, Muntaner C. Examining associations between job characteristics and health: linking data from the Occupational Information Network (O* NET) to two US national health surveys. J Occup Environ Med. 2008;50(12):1401-13.

13. Greenhaus JH, Powell GN. Making work and family work: from hard choices to smart choices. New York: Routledge; 2016.

14. Savin-Baden M, Howell-Major C. Qualititative research: the essential guide to theory and practice. Qualitative Research: The Essential Guide to Theory and Practice. Routledge, New York, 2013.

15. Speziale HS, Streubert HJ, Carpenter DR. Qualitative research in nursing: Advancing the humanistic imperative. Philadelphia: Lippincott Williams \& Wilkins; 2011

16. Hunt B. Publishing qualitative research in counseling journals. J Couns Dev. 2011;89(3):296-300.

17. Haverkamp BE, Young RA. Developing a rationale for qualitative research and formulating the research question. Couns Psychol. 2007;35(2):265-94

18. Hermann M, Neale-McFall C. Experiences of pretenure counseling professor mothers. NASPA J About Women Higher Educ. 2018;1 1(3):265-83.

19. Ibrahim Meleis A, Douglas MK, Eribes C, Shih F, Messias DK. Employed Mexican women as mothers and partners: valued, empowered and overloaded. J Adv Nurs. 1996;23(1):82-90.

20. Khalili Varankashi A. Evaluation of Psychometric Properties of Keyes Mental Health Questionnaire (short form-14 items) and its Relationship with Happiness Questionnaire. Master Thesis, Islamic Azad University. 2015.

21. Elo S, Kyngäs H. The qualitative content analysis process. J Adv Nurs. 2008:62(1):107-15.

22. Murdock M. The heroine's journey: woman's quest for wholeness. Berkeley: Shambhala Publications; 2020.

23. Qur'an H. Surah An-Nisa'. Verse

24. Caplow T. The sociology of work. 1954

25. Bonjean CM. Miller and form: industrial sociology: the sociology of work organizations (Book Review). Soc Forces. 1965;44(1):129.

26. Straiton ML, Ledesma HM, Donnelly TT. A qualitative study of Filipina immigrants'stress, distress and coping: the impact of their multiple, transnational roles as women. BMC Womens Health. 2017:17(1):1-1. 
27. Kimani E. The abundance versus scarcity mentality. Finance (Nairobi, Kenya). 2007:27-28.

28. Freebairn-Smith L. Abundance and scarcity mental models in leaders, Citeseer, Pennsylvania, 2010

29. Bianchi SM, Milkie MA. Work and family research in the first decade of the twenty-first century. J Marriage Family. 2010;72(3):705-25.

30. Eby LT, Casper WJ, Lockwood A, Bordeaux C, Brinley A. Work and family research in IO/OB: Content analysis and review of the literature (1980-2002). J Vocat Behav. 2005:66(1):124-97.

31. Powell GN. Women and men in management. London: Sage Publications; 2018.

32. Woodhill BM, Samuels CA. Positive and negative androgyny and their relationship with psychological health and well-being. Sex Roles. 2003;48(11):555-65.

33. Guastello DD, Guastello SJ. Androgyny, gender role behavior, and emotional intelligence among college students and their parents. Sex Roles. 2003;49(11):663-73.

34. Zhang J, Norvilitis JM, Jin S. Measuring gender orientation with the Bem Sex Role Inventory in Chinese culture. Sex Roles. 2001;44(3):237-51.

35. Mahalik JR, Burns SM, Syzdek M. Masculinity and perceived normative health behaviors as predictors of men's health behaviors. Soc Sci Med. 2007;64(11):2201-9.

36. Shockley KM, Shen W, DeNunzio MM, Arvan ML, Knudsen EA. Disentangling the relationship between gender and work-family conflict: an integration of theoretical perspectives using meta-analytic methods. J Appl Psychol. 2017;102(12):1601

37. Gillespie BB, Temple HS. Good enough is the new perfect: finding happiness and success in modern motherhood. Toronto: Harlequin; 2011.

38. Jung C. Lactivism: How feminists and fundamentalists, hippies and yuppies, and physicians and politicians made breastfeeding big business and bad policy. New York: Basic Books; 2015.

39. Nickols SY, Schulte B. Overwhelmed: work, love, and play when no one has the time. Farrar, Straus and Giroux, New York. ISBN: 978-0-374-22844-6 (2014)

40. Slaughter AM. Unfinished business: women men work family. New York: Simon and Schuster; 2015

41. Hochschild A, Machung A. The second shift: working families and the revolution at home. London: Penguin; 2012.

42. Motahhari M. The system of women's rights in Islam. Tehran; 1978, p. 78.

43. Baghdadi A, Nu'man MIM. Ahkam al-Nisa. Sheikh Mufid Millennium World Congress. "No Title." 1st ed. p 42 (Arabic) 41. 1993

44. Seyyed AH. Mahzab al-Ahkam fi Bayan al-Hilal WA al-Haram. Al-Manar Institute,"No Title. 4th ed. p 191 (Arabic) 43. 1993

45. Seyyed AH. Al-Masa'il al-Muntakhabeh. Office of Ayatollah Sistani, "No Title." 9th ed. p 391 (Arabic) 45. 2002

46. Hewitt B, Baxter J, Western M. Family, work and health: the impact of marriage, parenthood and employment on self-reported health of Australian men and women. J Sociol. 2006;42(1):61-78.

47. von der Lippe E, Rattay P. Association of partner, parental, and employment statuses with self-rated health among German women and men. SSM Popul Health. 2016:2:390-8

48. Hattar-Pollara M, Meleis Al, Nagib H. Multiple role stress and patterns of coping of Egyptian women in clerical jobs. J Transcult Nurs. 2003;14(2):125-33.

49. Barnett RC, Steptoe A, Gareis KC. Marital-role quality and stress-related psychobiological indicators. Ann Behav Med. 2005;30(1):36-43.
50. Floderus B, Hagman M, Aronsson G, Marklund S, Wikman A. Work status, work hours and health in women with and without children. Occup Environ Med. 2009;66(10):704-10.

51. Popham F, Gray L, Bambra C. Employment status and the prevalence of poor self-rated health. Findings from UK individual-level repeated crosssectional data from 1978 to 2004. BMJ Open. 2012;2(6):e001342.

52. Roos E, Lahelma E, Saastamoinen P, Elstad JI. The association of employment status and family status with health among women and men in four Nordic countries. Scand J Public Health. 2005;33(4):250-60.

53. Barnett RC, Hyde JS. Women, men, work, and family: an expansionist theory. Am Psychol. 2001;56(10):781.

54. Covey SR. Daily reflections for highly effective people: living the seven habits of highly successful people every day. New York: Simon and Schuster; 1994.

55. Schwabenland C, Tomlinson F. Managing diversity or diversifying management? Crit Perspect Int Bus. 2008:4(2/3):320-33.

56. Pastor J. Empowerment: what it is and what it is not. Empower Org 1996:4:2-7.

57. Honold L. A review of the literature on employee empowerment. Empower Org. 1997:5(4):202-12.

58. Duffy RD, Dik BJ. Research on calling: What have we learned and where are we going? J Vocat Behav. 2013;83(3):428-36.

59. Bunderson JS, Thompson JA. The call of the wild: Zookeepers, callings, and the double-edged sword of deeply meaningful work. Adm Sci Q. 2009;54(1):32-57.

60. Hagmaier T, Abele AE. The multidimensionality of calling: conceptualization, measurement and a bicultural perspective. J Vocat Behav. 2012;81(1):39-51

61. Sham T, Tram S, Ohara LA. Relation of employee and manager emotional intelligence to job satisfaction and performance. J Vocat Behav. 2006:68(3):461-73.

62. Cazan AM, Năstasă LE. Emotional intelligence, satisfaction with life and burnout among university students. Proc Soc Behav Sci. 2015;180:1574-8.

63. Mikolajczak M, Luminet O. Trait emotional intelligence and the cognitive appraisal of stressful events: an exploratory study. Personal Individ Differ. 2008:44(7):1445-53.

64. Ashmos DP, Duchon D. Spirituality at work: a conceptualization and measure. J Manag Inquiry. 2000;9(2):134-45

65. Hyson P. The spirited leader: the potential of spiritual intelligence to improve leadership. Int J Leadersh Public Serv. 2013

66. Koenig HG. Religion, spirituality, and health: a review and update. Adv Mind-Body Med. 2015;29(3):19-26.

67. McKee MC, Driscoll C, Kelloway EK, Kelley E. Exploring linkages among transformational leadership, workplace spirituality and well-being in health care workers. J Manag Spiritual Relig. 2011;8(3):233-55.

68. Unterrainer HF, Lewis AJ, Fink A. Religious/spiritual well-being, personality and mental health: a review of results and conceptual issues. J Relig Health. 2014;53(2):382-92.

69. Beehr TA, Newman JE. Job stress, employee health, and organizational effectiveness: a facet analysis, model, and literature review 1. Pers Psychol. 1978:31(4):665-99.

\section{Publisher's Note}

Springer Nature remains neutral with regard to jurisdictional claims in published maps and institutional affiliations. 